\title{
Research and Development of Dual Functional Features of Light-Emitting Diode: Degradation of Atmospheric Fine Particulate Matter and Antimicrobial Efficacy
}

\author{
Tzu Yun Chi ${ }^{1 \#}$, Cho-Lin Li ${ }^{1 \#}$, Cheng Sheng Tsung ${ }^{2 \#}$, Chia Chi Chen ${ }^{1}$, Ying Ching Hung ${ }^{1}$, Chia Yu \\ Lin $^{1}$, Yu Wen Hung ${ }^{3}$, Ching Feng Chiu ${ }^{4}$, Chien Chao Chiu ${ }^{1}$, Hsuan Wen Chiu ${ }^{5}$, Yu Hsing Lin ${ }^{6}$, \\ Wei Huang Tsai ${ }^{7}$, Jyh Shiun Lin $^{1}$ and Shao Wen Hung ${ }^{1,6^{*}}$
}

${ }^{1}$ Division of Animal Industry, Animal Technology Laboratories, Agricultural Technology Research Institute, Xiangshan, Hsinchu 300, Taiwan

${ }^{2}$ Department of Materials Science and Engineering, National Chung Hsing University, Taichung 402, Taiwan

${ }^{3}$ Institute of Cellular and System Medicine, National Health Research Institutes, Maioli 350, Taiwan

${ }^{4}$ Graduate Institute of Metabolism and Obesity Sciences, College of Nutrition, Taipei Medical University, Taipei 110, Taiwan

${ }^{5}$ Department of Biotechnology and Bioindustry Sciences, College of Bioscience and Biotechnology, National Cheng Kung University, Tainan 701, Taiwan

${ }^{6}$ Nursing Department of Yuanpei University, Xiangshan, Hsinchu 300, Taiwan

${ }^{7}$ Department of Science and Technology, Council of Agriculture, Executive Yuan, Taipei 100, Taiwan

*Corresponding author: Shao Wen Hung, Division of Animal Industry, Animal Technology Laboratories, Agricultural Technology

Research Institute; Nursing Department, Xiangshan, Hsinchu 300, Taiwan

\section{ARTICLE INFO}

Received: 㓞 August 13, 2019

Published: 幽 August 20, 2019

Citation: Tzu Yun Chi, Cho Lin Li, Cheng Sheng Tsung, Chia Chi Chen, Ying Ching Hung, Chia Yu Lin, Yu Wen Hung, Ching Feng Chiu, Chien Chao Chiu, HsuanWen Chiu, Yu Hsing Lin, Wei Huang Tsai, Jyh Shiun Lin, Shao Wen Hung. Research and Development of Dual Functional Features of Light-Emitting Diode: Degradation of Atmospheric Fine Particulate Matter and Antimicrobial Efficacy. Biomed J Sci \& Tech Res 20(4)2019. BJSTR. MS.ID.003491.

Keywords: Antimicrobial Efficacy; Atmospheric Fine Particulate Matter; Degradation; In vitro; Light-Emitting Diode; Staphylococcus aureus; Pseudomonas aeruginosa

\section{ABSTRACT}

Light-emitting diode (LED) is a semiconductor light source. LED in biomedical application as photodynamic therapy which induces cell death by the production of cytotoxic reactive oxygen species. Therefore, this principle of cell death can be also utilized to kill bacteria in vitro. Moreover, the R\&D of the novel functional ability of LED is need as degradation of atmospheric fine particulate matter, $\mathrm{PM}_{25}$ for LED industry development. Herein, we propose the use of white and blue LED devices at $450 \mathrm{~nm}$ wavelength as the powerful light source for in vitro killing of Staphylococcus aureus and Pseudomonas aeruginosa, and degrading atmospheric fine particulate matter, $\mathrm{PM}_{2.5}$. Square arranged 48-white and blue LED array was respectively designed as the light source to fit exactly $10 \mathrm{~cm}$ culture plate and the degradation assay of $\mathrm{PM}_{2.5}$ was also performed. Both Staphylococcus aureus and Pseudomonas aeruginosa were order from ATCC in this study. Effects of this powerful LED devices on viability of these bacterial species and degradation assay of $\mathrm{PM}_{2.5}$ were compared with control samples. Statistical analysis was done using Microsoft Excel Student's $t$ test. Results showed that the powerful LED devices against both Staphylococcus aureus and Pseudomonas aeruginosa was significantly effective compared to control samples in vitro. Degradation efficacy of $\mathrm{PM}_{2.5}$ was also found after LED lighting. Taken together, the dual functional features, $\mathrm{PM}_{2.5}$ degradation and antimicrobial efficacy, of our LED devices were demonstrated in this study. In the future, this powerful LED devices has promising applications in the human and animal life environment and in the biomedical application as disinfection, bacteriostatic, and improvement of air quality.

Abbreviations: LED: Light-Emitting Diode; MRSA: Methicillin-Resistant Staphylococcus Aureus; PA: Pseudomonas Aeruginosa; ROS: Reactive Oxygen Species; PDI: Photodynamic Inactivation; UV: Ultraviolet 
Antimicrobial LED Visible Light is Safer than Ultraviolet Light

Ultraviolet (UV) light has been developed for surface decontamination. However, UV light has some limitations at harmful effects for human and animals [1-2]. Previously, some studies have been demonstrated that the germicidal efficacy of $405 \mathrm{~nm}$ light is significantly lower than that of UV light [3-5]. Visible light at $405 \mathrm{~nm}$ wavelength can be used at lethal levels to microorganisms without affecting exposed mammalian cells [6-7]. Light-emitting diode (LED) is a cost-effective semiconductor device that produces light within a narrow bandwidth of wavelength through electroluminescence. Recently, LED technology has attention to apply in the area of food production, food preservation, and food safety [8-9]. At present, some researches have been demonstrated that the antimicrobial LED visible light is less antimicrobial efficacy than UV light $[7,10]$. However, the antimicrobial LED visible light has been recognized as an alternative technology to UV light since it is an environmentally friendly and safe technology for human and animals $[7,10]$. For this reason, LED technology has recently received attention in the field of microbiology due to its antimicrobial effect.

In particular, many researches have been demonstrated that LEDs with the certain wavelength have antimicrobial effects. In vitro lethality of blue light for the bacteria Escherichia coli, aerobic methicillin-resistant Staphylococcus aureus (MRSA), and Pseudomonas aeruginosa (PA) has also been reported [11-12]. The antimicrobial effect of LED at $400 \mathrm{~nm}$ wavelength has been also reported to be effective against Listeria monocytogenes and Salmonella typhimurium [13]. LEDs at 405, 460 and 520 $\mathrm{nm}$ wavelength have also demonstrated antibacterial effects against various foodborne pathogens [2,9,14-15]. Staphylococcus aureus is a common cause of food poisoning, and some strains of Staphylococcus aureus have acquired resistance against a range of antibiotics [16]. Maclean et al. [9] showed that a LED with 405 $\mathrm{nm}$ wavelength inactivated 56-90\% MRSA in the environment. In addition, De Lucca et al. [17] reported that blue light at $470 \mathrm{~nm}$ wavelength effectively inhibits bacterial (Leuconostoc mesenteroides, Bacillus atrophaeus, and PA) and fungal (Penicillium digitatum and Fusarium graminearum) growth.

\section{Mechanisms of LED Light for Antimicrobial Efficacy and $\mathrm{PM}_{2.5}$ Degradation}

Microbial inactivation via LED technology is commonly referred to as photodynamic inactivation by producing reactive oxygen species (ROS) to kill pathogens. The antimicrobial mechanisms commonly included type I and type II mechanism. Type I mechanism can produce superoxide anion $\left(\mathrm{O}_{2}^{-}\right)$and hydroxyl radical $(\bullet \mathrm{OH})$. Type II mechanism can excite the triplet oxygen to the reactive singlet oxygen. Due to these ROS generated a number of cytotoxic reactions and caused extensive damage to the cellular components. Absorption of this light results in the production of ROS, including $\mathrm{H}_{2} \mathrm{O}_{2}$ and singlet oxygen, leading to oxidative damage and cell death
$[5,18]$. Finally, this eventually leads to the bacterial destruction $[8,16,19]$. Jia et al. [20] and Zhu et al. [21] reported that hot season than cold season can produce a strong oxidative air condition. The positive $\mathrm{PM}_{2.5}-\mathrm{O}_{3}$ correlations prevailed for high air temperature samples, while the negative correlations were generally found in cold environments. High $\mathrm{O}_{3}$ concentrations in a strong oxidative air condition promoted the formation of secondary particles, which could decrease atmospheric $\mathrm{PM}_{2.5}$ concentration, which is in a positive correlation between $\mathrm{PM}_{2.5}$ and $\mathrm{O}_{3}$. Hence, whether the mechanism of LED for $\mathrm{PM}_{2.5}$ degradation is related with air temperature and $\mathrm{O}_{3}$ ? It is needed to further verify.

\section{Application Fields of Antimicrobial LED Visible Light}

Photodynamic inactivation (PDI) via the visible light inactivation is a non-thermal photophysical and photochemical reaction that requires visible light [22]. Application of photodynamic inactivation of pathogens are in many fields as food production, food preservation, food safety, and fruit storage [9]. Kim et al. [9] reported that $405 \pm 5 \mathrm{~nm}$ LED illumination causes photodynamic inactivation of Salmonella spp. Photodynamic therapy (PDT) was known as photosensitizers which induces cell death via producing cytotoxic ROS [23]. Blue LED devices are used as a light source which offers various advantages over other light sources (lasers, UV-lamp etc.) as large output, less thermal destruction, easy fabrication, large area illumination, and cost efficiency [24]. Blue LED light can penetrate soft tissue depth of 2-3 mm that can be used in treatment of superficial wound infections [23]. In addition, PDT with LED lamp (630 $\mathrm{nm}$ wavelength) is an effective supplement in root canal disinfection [25]. The 405, 460 and $520 \mathrm{~nm}$ LEDs proved more effective in inactivating the selected foodborne bacteria (Lactobacillus plantarum, Staphylococcus aureus, and Vibrio parahaemolyticus). The $405 \mathrm{~nm}$ LED showed the greatest antibacterial effect at the same level of energy dose [16]. On cancer medicine field, some researches have been previously demonstrated that photodynamic therapy using cancer designed photosensitizers and laser beams has been increasingly used in clinical medicine. The LED light induced cell damage was wavelength-dependent, but not energy-dependent [26-27].

\section{Research and Development of Dual Functional Features of Light-Emitting Diode}

According to our previous publication [27], our LED light at $450 \mathrm{~nm}$ wavelength can induce highly cytotoxic ability for colon cancer cell lines (HT-29 and CT-26) in vitro and significantly suppress the tumor growth in the CT-26-bearing mice in vivo [27]. The anti-tumor efficacy of our LED device (450 nm wavelength) may be also utilized to kill bacteria and degrade atmospheric fine particulate matter, $\mathrm{PM}_{2.5}$. Both Staphylococcus aureus and Pseudomonas aeruginosa were ordered from ATCC (https://www. atcc.org/). $\mathrm{PM}_{2.5}$ standard sample was order from Sigma-Aldrich (PM2547050). Under the antibacterial assay and the degradation assay of $\mathrm{PM}_{2.5}$, these data were showed that our LED device (white 
and blue lights; Figure 1) significantly possessed antibacterial and $\mathrm{PM}_{2.5}$ degradation efficacies (Table1 and Figure 2). Compare of blue/white LED light at $15 / 30 \mathrm{~cm}$ of light height and $8 \mathrm{~h}$ or 16 h-lighting, white LED light decreased anti-PA efficacy at 15/30 cm of light height following with lighting time increase; blue LED light increased anti-PA efficacy at $15 / 30 \mathrm{~cm}$ of light height following with lighting time increase. On the other hand, both white/blue LED light increased anti-SA efficacy at $15 \mathrm{~cm}$ of light height following with lighting time increase. At $30 \mathrm{~cm}$ of light height, both white/ blue LED light decreased anti-SA efficacy following with lighting time increase (Table 1) (Figures 1 \& 2).
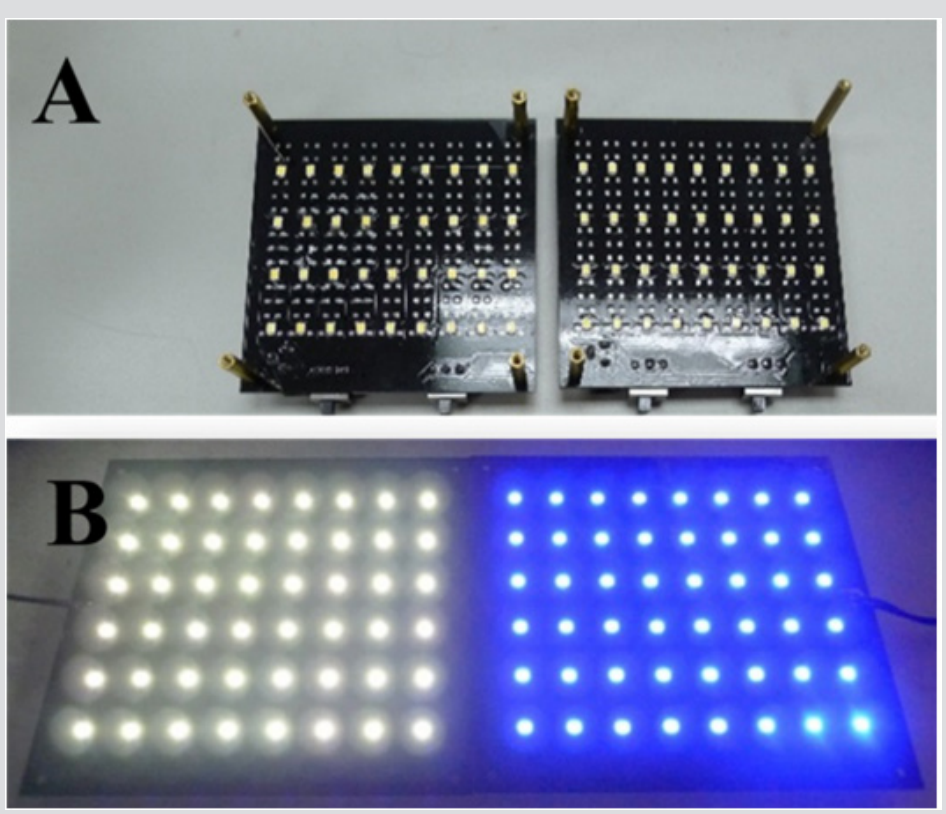

Figure 1: LED device

(A) Appearance of LED device. (B) White and blue visible light.

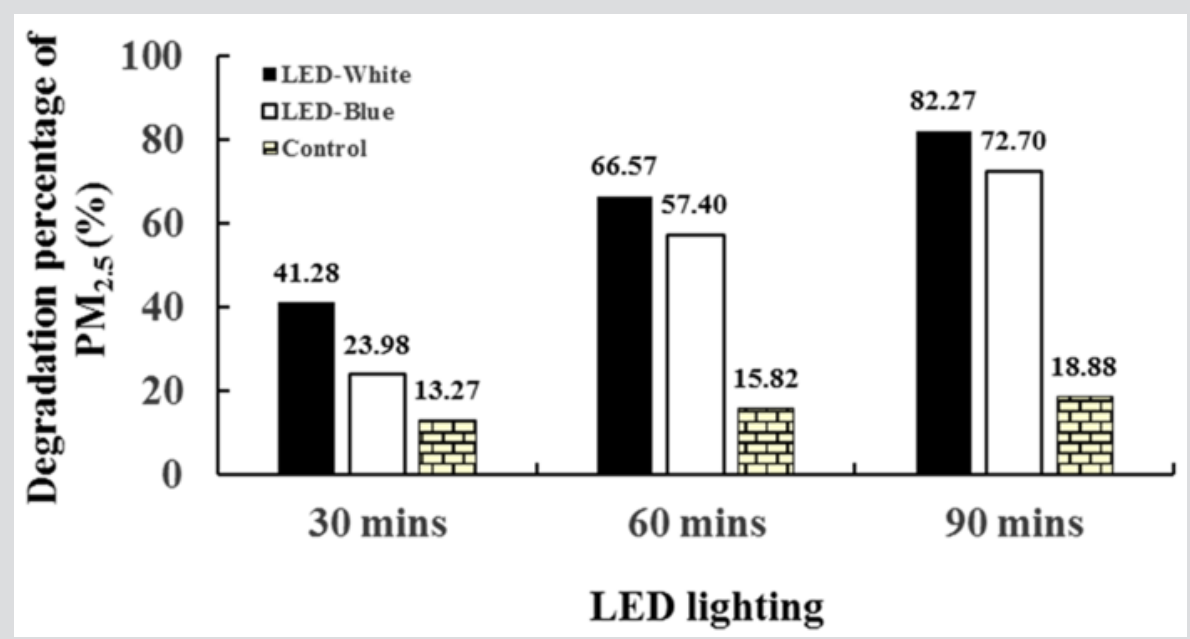

Figure 2: Degradation of $\mathrm{PM}_{2.5}$ by LED device (White and blue visible light at $450 \mathrm{~nm}$ wavelength).

Table 1: Antibacterial efficacy of our LED device (Blue and white light at $450 \mathrm{~nm}$ wavelength).

\begin{tabular}{|c|c|c|c|c|}
\hline \multirow{2}{*}{$\begin{array}{c}\text { Lighting Height/Lighting } \\
\text { Time }\end{array}$} & LED Light Color & Illuminance (lux) & \multicolumn{2}{|c|}{ Antibacterial Efficacy (\%) } \\
\cline { 3 - 5 } & & & PA & SA \\
\hline \multirow{2}{*}{$15 \mathrm{~cm} / 8 \mathrm{~h}$} & QT-White & 23,200 & 47.47 & 47.00 \\
\cline { 2 - 5 } & QT-Blue & 956 & 85.57 & 39.90 \\
\hline \multirow{2}{*}{$30 \mathrm{~cm} / 8 \mathrm{~h}$} & QT-White & 8,828 & 89.08 & 24.34 \\
\cline { 2 - 5 } & QT-Blue & 462 & 48.45 & 21.21 \\
\hline \multirow{2}{*}{$15 \mathrm{~cm} / 16 \mathrm{~h}$} & QT-White & 23,200 & 40.14 & 41.18 \\
\hline
\end{tabular}




\begin{tabular}{|l|c|c|c|}
\hline \multirow{2}{*}{$30 \mathrm{~cm} / 16 \mathrm{~h}$} & QT-White & 8,828 & 46.99 \\
\cline { 2 - 4 } & QT-Blue & 462 & 53.70 \\
\hline
\end{tabular}

Abbreviation: Light-emitting diode (LED); Pseudomonas aeruginosa (PA); Quantum (QT); Staphylococcus aureus (SA)

\section{Conclusion}

The dual functional features, degradation of atmospheric fine particulate matter, $\mathrm{PM}_{2.5}$ and antimicrobial efficacy, in our LED device were first demonstrated in this study. In the future, this powerful LED devices have the promising applications in the human and animal life environment and biomedical application to serve as disinfection, bacteriostatic, and improvement of air pollutions.

\section{Acknowledgement}

All authors thank the Council of Agriculture in Taiwan (Executive Yuan) [grant numbers 108AS-14.1.2-ST-a7]; All authors also thank the cooperation team members, Geeder Co. Ltd.; Shinkong Technologies. Co. Ltd.; Hong Zhao Co., Ltd., for fully supporting this study.

\section{Reference}

1. Maclean M, MacGregor SJ, Anderson JG, Woolsey G (2009) Inactivation of bacterial pathogens following exposure to light from a 405-nanometer light-emitting diode array. Appl Environ Microbiol 75(7): 1932-1937.

2. Kim MJ, Mikš Krajnik M, Kumar A, Yuk HG (2016) Inactivation by 405 $\pm 5 \mathrm{~nm}$ light emitting diode on Escherichia coli 0157: H7, Salmonella Typhimurium, and Shigella sonnei under refrigerated condition might be due to the loss of membrane integrity. Food Control 59: 99-107.

3. Li J, Hirota K, Yumoto H, Matsuo T, Miyake Y, et al. (2010) Enhanced germicidal effects of pulsed UV-LED irradiation on biofilms. J Appl Microbiol 109(6): 2183-2190.

4. Wengraitis S, McCubbin P, Wade MM, Biggs TD, Hall S, et al. (2013) Pulsed UV-C disinfection of Escherichia coli with light-emitting diodes, emitted at various repetition rates and duty cycles. Photochem Photobiol 89(1): 127-131.

5. Gillespie JB, Maclean M, Given MJ, Wilson MP, Judd MD, et al. (2017) Efficacy of pulsed 405-nm light-emitting diodes for antimicrobial photodynamic inactivation: effects of intensity, frequency, and duty cycle. Photomed Laser Surg 35(3): 150-156.

6. Dai T, Gupta A, Huang YY, Yin R, Murray CK, et al. (2013) Blue light rescues mice from potentially fatal Pseudomonas aeruginosa burn infection: efficacy, safety, and mechanism of action. Antimicrob Agents Chemother 57(5): 1238-1245.

7. McDonald RS, Gupta S, Maclean M, Ramakrishnan P, Anderson JG, et al. (2013) $405 \mathrm{~nm}$ Light exposure of osteoblasts and inactivation of bacterial isolates from arthroplasty patients: potential for new disinfection applications? Eur Cell Mater 25: 204-214.

8. Luksiene Z, Brovko L (2013) Antibacterial photosensitization-based treatment for food safety. Food Eng Rev 5(4): 185-199.

9. Kim MJ, Bang WS, Yuk HG (2017) $405 \pm 5$ nm light emitting diode illumination causes photodynamic inactivation of Salmonella spp. on fresh-cut papaya without deterioration. Food Microbiol 62: 124-132.

10. Luksienè Z, Zukauskas A (2009) Prospects of photosensitization in control of pathogenic and harmful micro-organisms. J Appl Microbiol 107(5): 1415-1424.

11. Guffey JS, Wilborn J (2006) Effects of combined 405-nm and 880-nm light on Staphylococcus aureus and Pseudomonas aeruginosa in vitro. Photomed Laser Surg 24(6): 680-683.
12. Brovko LY, Meyer A, Tiwana AS, Chen W, Liu H, et al. (2009) Photodynamic treatment: a novel method for sanitization of food handling and food processing surfaces. J Food Prot 72(5): 1020-1024.

13. Luksiené Z, Kokstaite R, Katauskis P, Skakauskas V (2013) Novel approach to effective and uniform inactivation of Gram-positive Listeria monocytogenes and Gram-negative Salmonella enterica by photosensitization. Food Technol Biotech 51(3): 338-344.

14. Ghate V, Ng KS, Zhou W, Yang H, Khoo GH, et al. (2013) Antibacterial effect of light emitting diodes of visible wavelengths on selected foodborne pathogens at different illumination temperatures. Int J Food Microbiol 166(3): 399-406

15. Kumar A, Ghate V, Kim MJ, Zhou W, Khoo GH, et al. (2016) Antibacterial efficacy of 405, 460 and $520 \mathrm{~nm}$ light emitting diodes on Lactobacillus plantarum, Staphylococcus aureus and Vibrio parahaemolyticus. J Appl Microbiol 120(1): 49-56.

16. Kumar A, Ghate V, Kim MJ, Zhou W, Khoo GH, et al. (2015) Kinetics of bacterial inactivation by $405 \mathrm{~nm}$ and $520 \mathrm{~nm}$ light emitting diodes and the role of endogenous coproporphyrin on bacterial susceptibility. J Photochem Photobiol B 149: 37-44.

17. De Lucca AJ, Carter Wientjes C, Williams KA, Bhatnagar D (2012) Blue light (470 nm) effectively inhibits bacterial and fungal growth. Lett Appl Microbiol 55(5): 460-466.

18. Ramakrishnan P, Maclean M, MacGregor SJ, Anderson JG, Grant MH (2016) Cytotoxic responses to $405 \mathrm{~nm}$ light exposure in mammalian and bacterial cells: involvement of reactive oxygen species. Toxicol In Vitro 33: 54-62.

19. Luksiene Z (2009) Photosensitization for food safety. Chemine Technologija 4: 62-65.

20. Jia M, Zhao T, Cheng X, Gong S, Zhang X, et al. (2017) Inverse relations of $\mathrm{PM}_{2.5}$ and $\mathrm{O}_{3}$ in air compound pollution between cold and hot seasons over an urban area of East China. Atmosphere 8(3): 59.

21. Zhu J, Chen L, Liao H, Dang R (2019) Correlations between $\mathrm{PM}_{2.5}$ and Ozone over China and associated underlying reasons. Atmosphere10(7): 352 .

22. Dai T, Fuchs BB, Coleman JJ, Prates RA, Astrakas C, et al. (2012) Concepts and principles of photodynamic therapy as an alternative antifungal discovery platform. Front Microbiol 3: 120.

23. Thakuri PS, Joshi R, Basnet S, Pandey S, Taujale SD, et al. (2011) Antibacterial photodynamic therapy on Staphylococcus aureus and Pseudomonas aeruginosa in-vitro. Nepal Med Coll J 13(4): 281-284.

24. Luksiene Z (2005) New approach to inactivation of harmful and pathogenic microorganisms by photosensitization. Food Technol Biotechnol 43(4): 411-418.

25. Asnaashari M, Mojahedi SM, Asadi Z, Azari Marhabi S, Maleki A (2016) A comparison of the antibacterial activity of the two methods of photodynamic therapy (using diode laser $810 \mathrm{~nm}$ and LED lamp 630 $\mathrm{nm}$ ) against Enterococcus faecalis in extracted human anterior teeth. Photodiagnosis Photodyn Ther 13: 233-237.

26. Sparsa A, Faucher K, Sol V, Durox H, Boulinguez S, et al. (2010) Blue light is phototoxic for B16F10 murine melanoma and bovine endothelial cell lines by direct cytocidal effect. Anticancer Res 30(1): 143-148.

27. Hung YW, Tsung CS, Lin YH, Chiu CF, Chiu CC, et al. (2019) Study of phototoxicity of LED light for colon cancer. Biomed J Sci Tech Res 13(4): 10167-10169. 


\section{ISSN: 2574-1241}

DOI: $10.26717 /$ BJSTR.2019.20.003491

Shao Wen Hung. Biomed J Sci \& Tech Res

(C) This work is licensed under Creative

Submission Link: https://biomedres.us/submit-manuscript.php

$\begin{array}{ll}\text { BIOMEDICAL } & \text { Assets of Publishing with us } \\ \text { RESEARCHES } & \text { - Global archiving of articles } \\ \text { - Immediate, unrestricted online access } \\ \text { - Rigorous Peer Review Process }\end{array}$

